\title{
Rheological Properties and Its Effect on the Lubrication Mechanism of PVP K30 and PVP 40-50 G as Artificial Synovial Fluids
}

\author{
Ankit Kotia ${ }^{1}$, Sunil More ${ }^{1}$, Aman Yadav ${ }^{1}$, Thota Venkata Sai Yaswanth Mohan ${ }^{1}$, \\ Arnepaplli Harshavardhan Naidu ${ }^{1}$, Golusu Rajesh ${ }^{1}$ and Ioannis E. Sarris ${ }^{2, *(1)}$ \\ 1 School of Mechanical Engineering, Lovely Professional University, Punjab 144411, India; \\ ankit.22697@lpu.co.in (A.K.); sunil.more@dyptc.edu.in (S.M.); amanyaadav.097@gmail.com (A.Y.); \\ yashwanthmohan7@gmail.com (T.V.S.Y.M.); harshavardhannaidu366@gmail.com (A.H.N.); \\ rgolusu98@gmail.com (G.R.) \\ 2 Department of Mechanical Engineering, University of West Attica, 12244 Athens, Greece \\ * Correspondence: sarris@uniwa.gr
}

check for

updates

Citation: Kotia, A.; More, S.;

Yadav, A.; Mohan, T.V.S.Y.;

Naidu, A.H.; Rajesh, G.; Sarris, I.E.

Rheological Properties and Its Effect on the Lubrication Mechanism of PVP K30 and PVP 40-50 G as Artificial Synovial Fluids. Inventions 2021, 6, 61. https://doi.org/10.3390/ inventions 6040061

Academic Editor: Rahmat Ellahi

Received: 25 August 2021

Accepted: 23 September 2021

Published: 27 September 2021

Publisher's Note: MDPI stays neutral with regard to jurisdictional claims in published maps and institutional affiliations.

Copyright: (c) 2021 by the authors. Licensee MDPI, Basel, Switzerland. This article is an open access article distributed under the terms and conditions of the Creative Commons Attribution (CC BY) license (https:/ / creativecommons.org/licenses/by/ $4.0 /)$.

\begin{abstract}
The effect of polyvinylpyrrolidone (PVP) on the rheological properties of joint prostheses is still unclear, despite its good lubricity and biocompatibility. In the present work, PVP K30 and PVP 40-50 G solutions at different concentrations were analyzed for rheological and lubrication properties. The rheological properties of the samples were measured at a shear rate range of 0-1800 s ${ }^{-1}$ (advanced air bearing rheometer Bohlin Gemini 2 and Plate MCR 72/92 rheometer for PVP30 and PVP 40-50 G, respectively). It was found that both the viscosity and shear stress of the samples reduced with a shear rate increase. PVP 40-50 G/sterile water showed higher viscosity as compared to the PVP K30/sterile water sample at a lower shear rate. However, at a higher shear rate, the PVP K30 sample produced better results. Further numerical study results showed the pressure and molecular viscosity distributions. The inclusion of PVP improved the load caring capacity and hence, it is a promising lubrication additive for artificial joints.
\end{abstract}

Keywords: synovial fluid; PVP K30; PVP 40-50 G; rheology

\section{Introduction}

Synovial fluid is a non-Newtonian fluid encapsulated in the synovial cavity of the major joints of human and animal bodies [1]. Its major functions include cushioning and steady load absorption during loading and providing a minimum coefficient of friction for smooth movement between the bones of the joint [2]. This behavior of synovial fluid is attributed to its viscoelastic-shear thinning fluid, which is mainly due to the presence of hyaluronic acid (HA), lubricin, serum albumin, and globulin [3]. The interaction between these molecules results in synovial fluid's boundary layer formation during less shear and elasto-hydrodynamic behavior during high shear [4]. The presence of synovial fluid between cartilages and bones ensures smooth operation of the joint. The occurrence of rheumatoid arthritis/osteoarthritis causes an alteration in the property and/or concentration of HA, lubricin, serum albumin, and globulin.

Osteoarthritis is quite a common problem in older age, especially in the hip joint and the knee joints due to heavy loading [4]. In this disease, there is significant alteration of the properties and concentration of synovial fluid. This change is related to the decrease in the concentration of HA and its molecular properties [5]. In order to restore it, viscosupplementation and non-steroidal anti-inflammatory drugs are widely employed [6]. Although such treatments promise better results, a reliable solution has always been in question. Studies investigating polyvinyl pyrrolidone (PVP) as an artificial joint lubricant are a stepping stone in this direction [7]. 
PVP is a synthetic polymer, which is developed by the radical polymerization of $\mathrm{N}$-vinyl-pyrrolidone [8]. Due to its inert, non-ionic, non-toxic, temperature-resistant, $\mathrm{pH}$ stable, biocompatible, and biodegradable nature [9], it has been used as blood plasma substitutes as well as in articular cartilages, shellac resin as a hair fixative agent, cosmetics and food industry, and biomedical applications $[9,10]$. Generally, the $\mathrm{k}$ value is used to denote it as PVP K10, PVP K20, etc. The $\mathrm{k}$ value indicates the viscosity of the different grades of PVP solutions, which depends on the degree of polymerization and molecular weight. Various grades of PVP have been tested [11] and classified on the basis of the molecular weight (range 2500-3,000,000 Daltons) they possess [9]. These grades perform in different manners when placed under shear stress. The range of their viscosity and other properties can vary significantly and therefore, not all these grades are suitable for use in joint lubrication.

Figure 1 display the molecular structure of PVP, which distinctly presents the various kinds of bonds that are established between atoms of oxygen, hydrogen, and more such elements. Table 1 shows the physicochemical properties of PVPs [9,12-14].

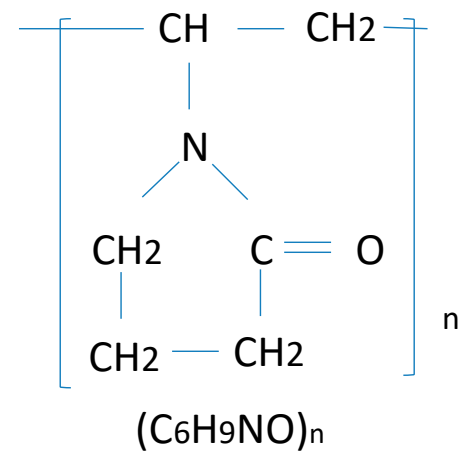

Figure 1. Molecular structure of PVP.

Table 1. Physicochemical properties of PVP $[9,12-14]$.

\begin{tabular}{cr}
\hline Property & \multicolumn{1}{c}{ Description } \\
\hline $\begin{array}{c}\text { Description of PVP } \\
\text { Molecular formula }\end{array}$ & Fine, white odorless, hygroscopic, Amorphous powder. \\
\hline Molecular weight & $2500-3,000,000 \mathrm{Da}$ \\
\hline K value range & $10-120$ \\
\hline Solubility & $\begin{array}{c}\text { Water, ethanol, methanol, chloroform, acids, and amines. Insoluble in } \\
\text { ethers, hydrocarbons, some esters, some ketones, and mineral oil. }\end{array}$ \\
\hline Melting point & Softens at $150{ }^{\circ} \mathrm{C}$ and decomposes after $180{ }^{\circ} \mathrm{C}$ \\
\hline pH value & 3-7 (varies with concentration and k value of the solution) \\
\hline Compatibility & Hydrophilic and hydrophobic, natural and synthetic resins; inorganic \\
salts and other chemicals.
\end{tabular}

Since the 1950s, PVPs' contribution has been expanding from biomedical $[15,16]$ and pharmaceutical $[16,17]$ applications to the cosmetics and food industry $[13,18]$. In 1971, Eric et al. performed an in vitro test to analyze the possibility of using silicone fluid, methyl cellulose, and polyvinyl-pyrrolidone as artificial lubricants for joints [10]. The study concluded that PVP displayed a persistent lubricating advantage over the other options. Not only was its performance far better, but it also exhibited lucrative boundary lubrication, which established its chance to be used as a possible lubricant in joints. This establishes the possibility of using PVP as a prominent artificial lubricant in human body joints. In 2015, Guo et al. [19] analyzed PVP K30 (Mol. Wt. 40,000 g/mol) based on three main parameters, namely viscosity, surface tension, and static contact angle, using five 
different concentrations and in two different solutions by using bovine serum solution and deionized water. Due to the encouraging results, their analysis concluded that utilizing PVP in artificial joints was a very practical and considerable choice. Table 2 shows a list of the relative viscosity range in $\mathrm{mPa} \cdot \mathrm{s}$ for PVPs of different grades and in different concentrations in water [9]. The relative viscosities listed act as a reference to select the proper grade of PVP for usage in various fields, such as cosmetic, food, and biomedical applications.

Table 2. Viscosity range of different grades of PVP concentrated in water [9].

\begin{tabular}{cccc}
\hline Polymer & K Value & Concentration in Water (\%) & Relative Viscosity in Water \\
\hline \multirow{4}{*}{ PVP } & 12 & 5 & $1.2915 \pm 0.0695$ \\
\cline { 2 - 4 } & 17 & 5 & $1.513 \pm 0.083$ \\
\cline { 2 - 4 } & 25 & 1 & $1.1735 \pm 0.0275$ \\
\cline { 2 - 4 } & 30 & 1 & $1.241 \pm 0.04$ \\
\hline
\end{tabular}

In the present study, both the viscosity and shear stress of PVP K30 and PVP 40-50 G solutions were experimentally and numerically evaluated for a range of shear rates. Initially, experimental analysis of the rheological properties followed by numerical study was performed.

\section{Experimental Method and Materials}

\subsection{Preparation Method of PVP Solution}

The samples of PVP K30 and PVP 40-50 G were procured from Sigma Aldrich (Burlington, MA, USA), which is a supplier of polymers for pharmaceutical applications, with an average molecular weight of 40,000 g/mol (PVP K30 and PVP 40-50 G) [19]. The samples were prepared with 0\%, 5\%-PVP40-50 G, 10\%-PVP K30, 20\%-PVP 40-50 G, and $20 \%$-PVP K30 in sterile water. The samples were prepared by dispersion of the measured volume fraction of PVP K30 and PVP 40-50 G into sterile water. The samples were prepared at room temperature and each sample was subjected to a stirrer at $300 \mathrm{rpm}$ for $15 \mathrm{~min}$ for homogenization.

\subsection{Rheological Measurements}

Rheological testing of the samples was performed on an Advanced Air Bearing Rheometer Bohlin Gemini 2 (Malvern Instruments, Malvern, United Kingdom) for PVP K30 and Cone \& Plate MCR 72/92 Rheometer (Anton Paar GmbH, Graz, Austria) for PVP 40-50 G. The testing was conducted at $37{ }^{\circ} \mathrm{C}$ to match the body temperature. The rheological properties were measured in the low to higher shear rate range.

\subsection{Numerical Analysis}

Numerical simulation in a rectangular model problem was performed on the computational fluid dynamics (CFD) FLUENT. The five cases were sterile water, 5\%-PVP 40-50 G/sterile water, 10\%-PVP K30/sterile water, 20\%-PVP40-50 G/sterile water, and 20\%-PVP K30/sterile water. Simulation was performed for a cuboid-shaped synovial fluid cavity model with the dimensions $10 \mathrm{~d} \times 2 \mathrm{~d} \times 1 \mathrm{~d}$ in length, width, and height, respectively, where $d$ is the height of the cavity. The geometry was divided into 160 elements in total with 315 nodes, as shown in Figure 2. The element size was set to the default, which acquired a value of $0.51 \mathrm{~mm}$. 


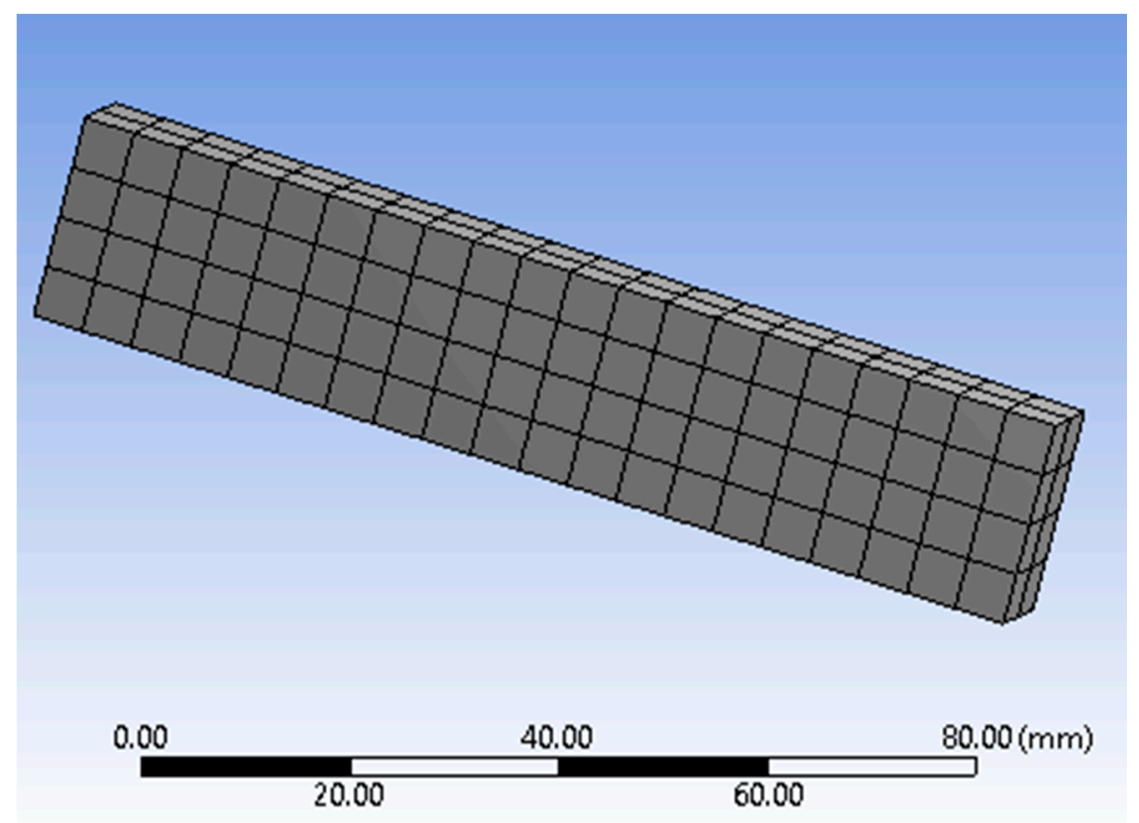

Figure 2. Domain and mesh distribution.

Figure 3 shows the variation in the maximum pressure value with the element size for sterile water. This grid independence test displayed that with a $0.55 \mathrm{~mm}$ to $0.53 \mathrm{~mm}$ element size, there was significant variation of the maximum pressure value. However, this variation was minimized with an element size of $0.51 \mathrm{~mm}$ and above. The test results indicated that an element size of $0.51 \mathrm{~mm}$ was ideal for the analysis to best fit the results accuracy and computational resources.

\section{Grid Independence test}

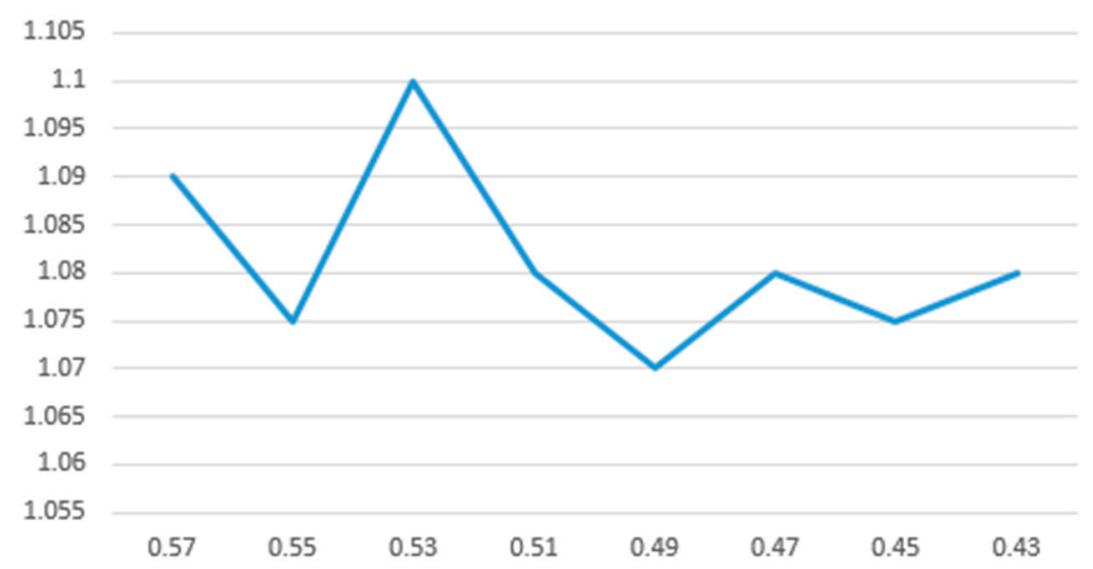

Figure 3. Grid independence test (x axis element size ( $\mathrm{mm})$ and y axis maximum pressure $(\mathrm{Pa})$.

A pressure-based solver with absolute velocity formulation was selected and gravity in the negative $\mathrm{z}$ direction was assigned to be $9.8 \mathrm{~m} / \mathrm{s}^{2}$. The fluid flow was assigned to be laminar [20]. Shear-dependent non-Newtonian fluid was selected, in which properties, such as the consistency index, power law index, and minimum/maximum viscosity limit, were taken from the experimental results. Equation (1) was used to find the viscosity of the non-Newtonian fluid. 
The following governing Equations (1)-(4) were used in the numerical study to obtain the values of the properties at varying loads and shear rates:

$$
\overline{\bar{\tau}}=\mu \overline{\bar{D}}
$$

where $\overline{\bar{\tau}}$ is the shear stress acting on the fluid, $\mu$ is the viscosity, and $\overline{\bar{D}}$ is the rate of the deformation tensor. The shear stress $(\tau)$ acting on the wall in the laminar flow is given by Equation (2):

$$
\tau=\mu \frac{\partial v}{\partial n}
$$

where $\frac{\partial v}{\partial n}$ is the gradient of velocity $\vec{v}$.

The steady-state continuity and momentum governing Equations (3) and (4), given by:

$$
\begin{gathered}
\rho \vec{v}=0 \\
\rho \vec{v} \vec{\nabla} v=-\nabla p+\nabla \overline{\bar{\tau}}+\vec{F}
\end{gathered}
$$

are solved, where $\rho$ is the density of the fluid, $\overline{\bar{\tau}}$ is the stress tensor, and $\vec{F}$ is the body force vector. Equation (5) was used to calculate the values of the fluid-consistency index $(m)$ and power law index $(n)$. The values were obtained by substituting experimental values of the shear rate and shear rate in the equation:

$$
\tau=\tau_{y}+m \gamma^{\cdot n}
$$

where $\tau_{y}$ is the yield stress.

Further, all terms in the equation are scalars, with $\gamma^{\circ}$ being the shear rate and $\tau$ being the second invariant of the stress tensor $\tau$.

For the well-tested model, proper boundary conditions were assigned, i.e., a uniformly distributed load of $5 \mathrm{MPa}$ on the inlet surface, which corresponds to a body weight of around $1000 \mathrm{~N}$ [21], and the rest surfaces as walls, and the residuals of the solver were set as the order of $10^{-3}$. A coupled scheme with second-order spatial discretization was used and the solution of the iterative solver was found after 300 iterations. A coupled algorithm was used to calculate the pressure-based continuity and momentum equations simultaneously, achieving converging criteria quickly for stead-steady flows. It was achieved through implicit discretization of the pressure gradient terms in the momentum equations.

Numerical studies were performed for the stance phase of normal gait. Stance is a simple yet a crucial phase for investigation in which the flow parameters of the synovial fluid are in laminar conditions $[20,21]$. Additionally, since the bones do not have any engaged movement in between them other than in the vertical direction, the movement in the $x$ and the $y$ directions is restricted. The loading conditions were calculated and verified as well, to be in accordance with previous studies [21], and then the analyses were carried out. It is to be kept in mind that lubrication in such conditions is restricted to boundary layer lubrication rather than elasto-hydrodynamic lubrication. It is characterized by a low shear rate value and a thin film of the fluid.

\section{Results and Discussion}

\subsection{Viscosity and Shear Stress}

The viscosity values and shear stress of the PVP solutions with different concentrations are shown in the following figures. Figure 4 shows the variation in shear stress and viscosity for the sterile water sample. As it can be observed, viscosity reduced with a shear rate increase while the shear stress increased. The sample data further proceeds to obtain the consistency and power law index, which are denoted by $m$ and $n$, respectively. The values of ' $m$ ' and ' $n$ ' are observed as $2.028302 \mathrm{~Pa} \cdot \mathrm{s}$ ' (where $\mathrm{n}$ is the flow behavior index) and 1.000357, respectively. 


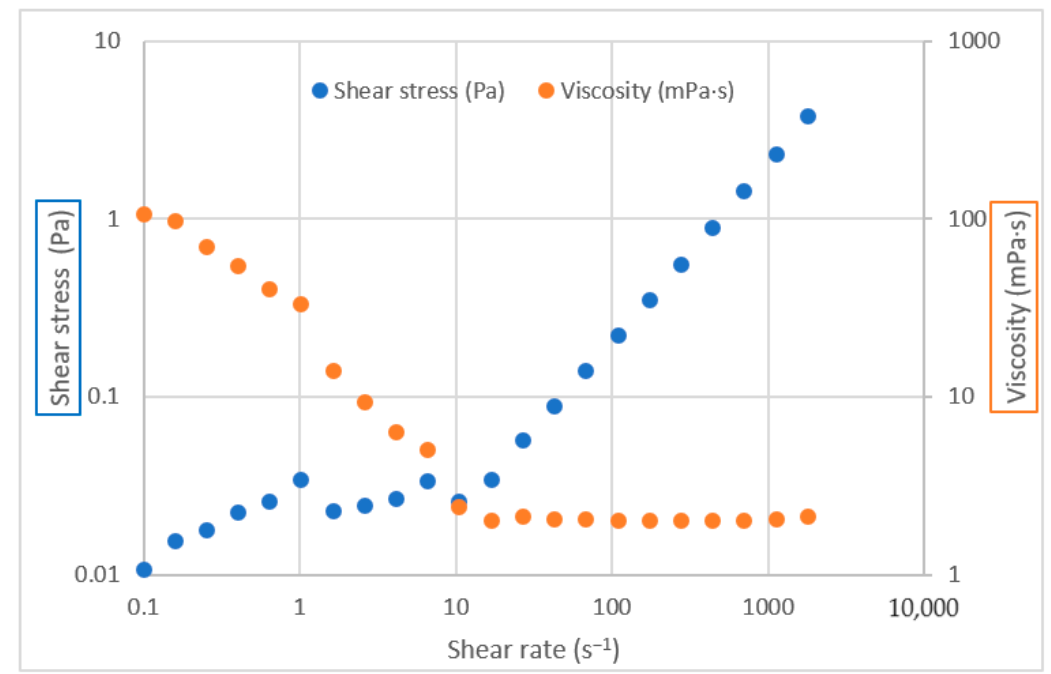

Figure 4. Rheological properties of the sterile water sample.

Figure 5 displays the variation in the shear stress and viscosity for the 5\%-PVP 40-50 G/sterile water sample. It can be observed that there is an almost six-fold increment in viscosity as compared to the sterile water samples at a lower shear rate. However, only a two-fold increment is observed at higher $\left(1800 \mathrm{~s}^{-1}\right)$ shear rates. This increment in viscosity may be helpful in improvement of the load bearing capacity. Similar incremental behavior is also observed in the shear stress values. There is an almost two-fold increment in shear stress with 5\%-PVP 40-50 G/sterile water compared to the sterile water samples at a higher shear rate. In detail, the $m$ and $n$ values obtained are $4.079838 \mathrm{~Pa} \cdot \mathrm{s}^{\mathrm{n}}$ and 1.002109 , respectively.

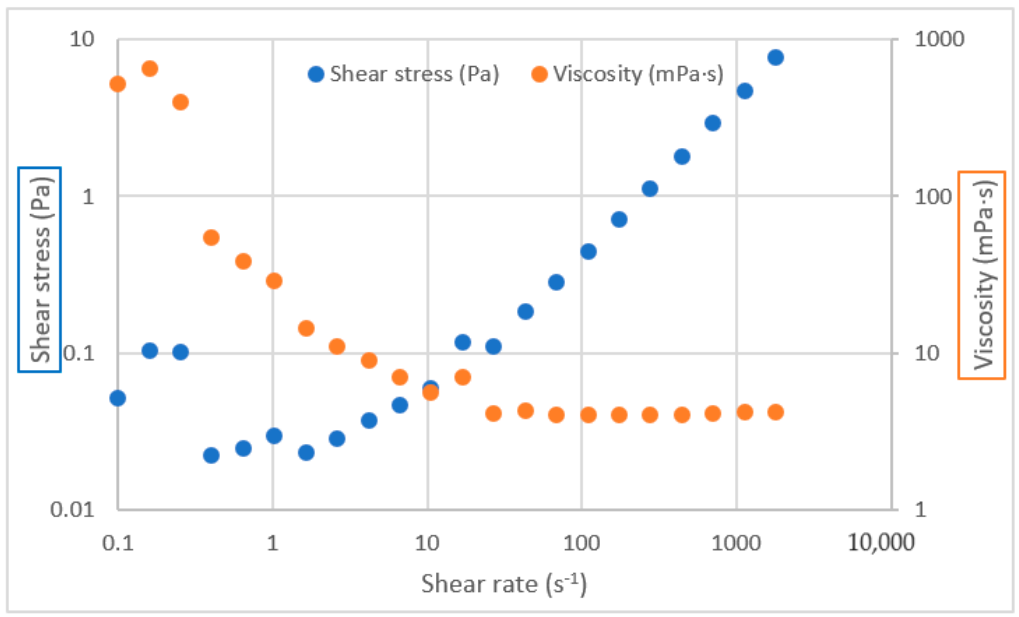

Figure 5. Rheological properties of the 5\%-PVP 40-50 G/sterile water sample.

Figure 6 displays the variation in viscosity and shear stress with shear rate for the $10 \%$ - PVP K30/sterile water sample. It can be observed that when a positive change was induced in the shear rate, the values of viscosity decreased in a steady fashion whereas the value of shear stress increased. Further, it can be observed that the viscosity of the $10 \%$ - PVP K30/sterile water sample is 2.7 times lower than the 5\%-PVP 40-50 G/sterile water sample at similar low shear rates. However, at the higher shear rate of $1533 \mathrm{~s}^{-1}$, the 10\%-PVP K30/sterile water sample shows higher viscosity (13.04 $\mathrm{mPa} \cdot \mathrm{s})$, as compared to the viscosity of the $5 \%$-PVP $40-50 \mathrm{G} /$ sterile water sample $\left(4.22 \mathrm{mPa} \cdot \mathrm{s}\right.$, at $\left.1130 \mathrm{~s}^{-1}\right)$. The sample shows values of $0.562050 \mathrm{~Pa} \cdot \mathrm{s}^{\mathrm{n}}$ and 1.420880 for the consistency $(\mathrm{m})$ and power law index $(n)$, respectively. 


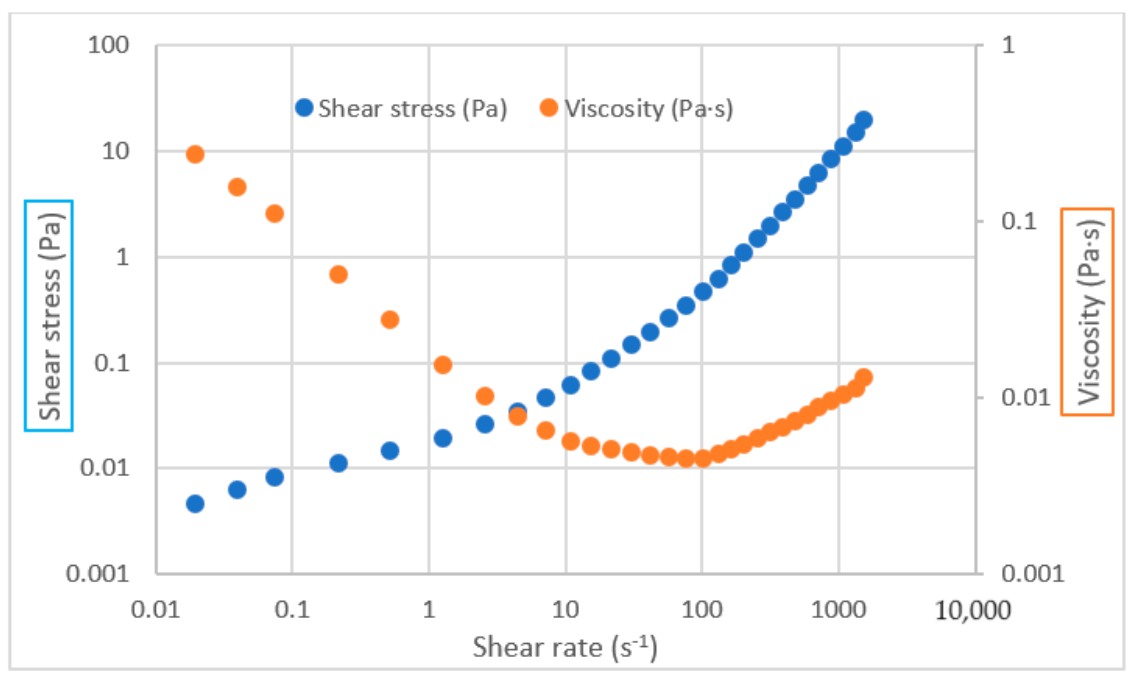

Figure 6. Rheological properties of the 10\%-PVP K30/sterile water sample.

Figures 7 and 8 display the variation in viscosity and shear stress with the shear rate for the 20\%-PVP 40-50 G/sterile water sample and 20\%-PVP K30/sterile water sample, respectively. It can be observed that at the same volume fraction (20\%), the PVP 40-50 G sterile water sample shows higher viscosity compared to the PVP K30/sterile water sample. However, it can be noticed that at the higher shear rate, the 20\%-PVP 40-50 G/sterile water $\left(1800 \mathrm{~s}^{-1}, 7.7 \mathrm{mPa} \cdot \mathrm{s}\right)$ sample shows lower viscosity as compared to the $20 \%-\mathrm{PVP}$ K30/sterile water sample (1497 $\left.\mathrm{s}^{-1}, 16.74 \mathrm{mPa} \cdot \mathrm{s}\right)$. This indicates that although the PVP K30/sterile water sample has lower viscosity at lower shear rates, the PVP K30/sterile water sample is higher as the shear rates increase. This indicates its better load bearing capacity in higher shear rate conditions.

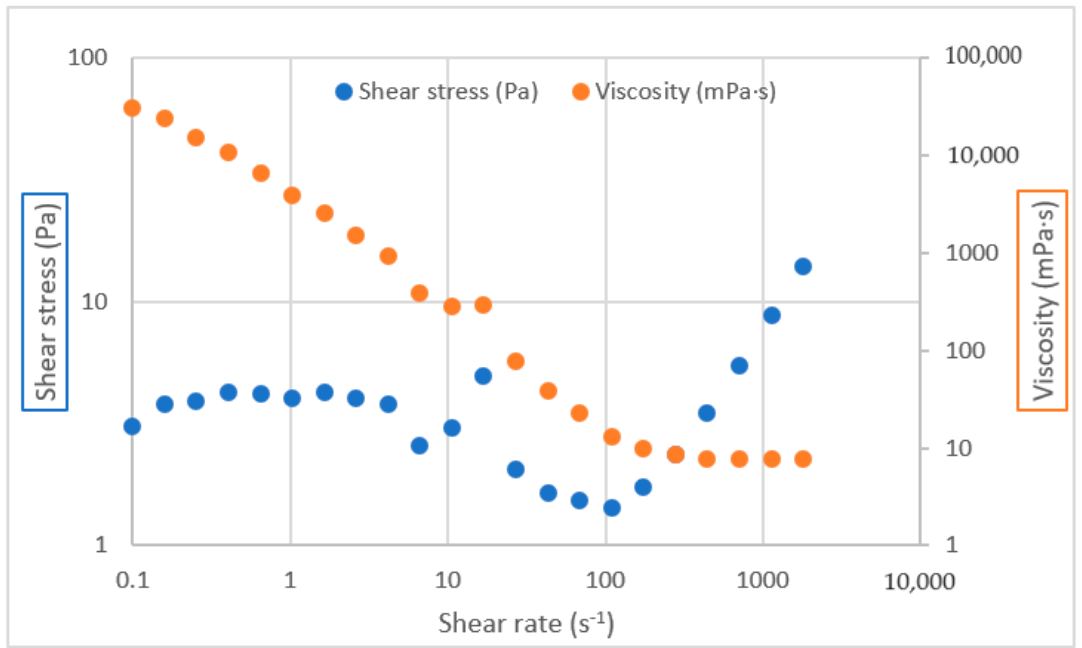

Figure 7. Rheological properties of the $20 \%$-PVP $40-50 \mathrm{G} /$ sterile water sample. 


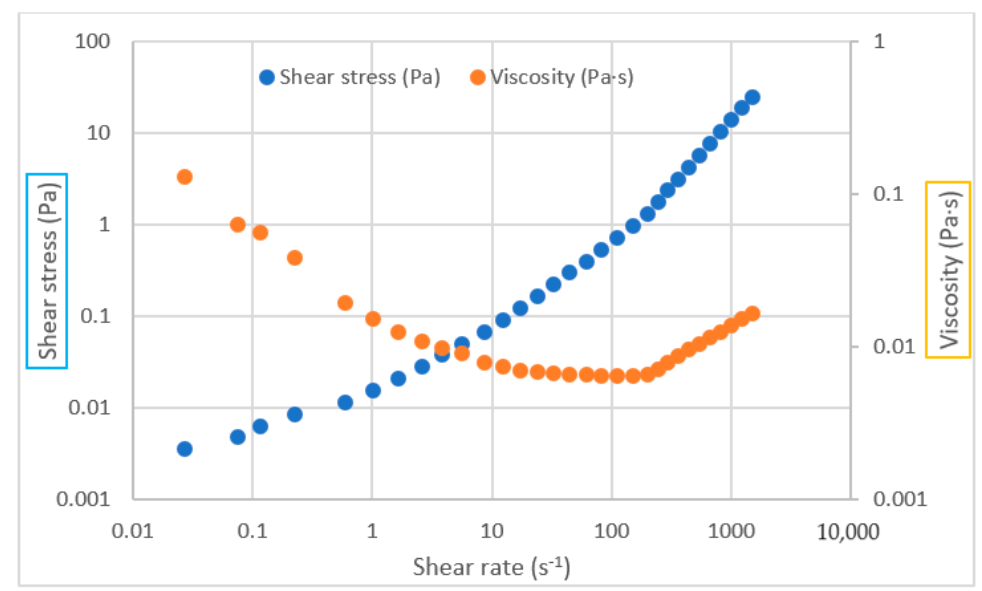

Figure 8. Rheological properties of the 20\%-PVP K30/sterile water sample.

\subsection{Numerical Analysis Results for Different Samples}

Table 3 shows the numerical analysis results for different samples with different value parameters. In each case, where the analysis for the various concentrations of PVP K30/sterile water and PVP 40-50 G/sterile water was performed for pressure variation, significantly varied results were observed. Since the viscosity variation and dynamics pressure variation are two of the most important parameters that can be analyzed to understand the non-Newtonian fluid behavior, they were studied graphically and their values are organized in Table 4.

Table 3. Graphical form of the numerical analysis results for different samples.

\begin{tabular}{|c|c|c|c|c|}
\hline & & sure (Pa) & & lar Viscosity $(\mathrm{kg} / \mathrm{m} \cdot \mathrm{s})$ \\
\hline & & & le water) & \\
\hline & F & Contours of Dynamic Pressure (pascal) & D & Contours of Molecular Viscosity $(\mathrm{kg} / \mathrm{m}-\mathrm{s}$ \\
\hline & 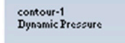 & & $\begin{array}{l}\text { comtour-2 } \\
\text { Molecular Viscosity }\end{array}$ & \\
\hline & $5.716=20$ & & $\square^{1066-01}$ & \\
\hline & s.14:-20 & & $1.066 \cdot 01$ & \\
\hline & $4.57=-30$ & & $\begin{array}{l}1.066 \cdot 01 \\
1066 \cdot 01\end{array}$ & \\
\hline & $4.000-30$ & & $\begin{array}{l}0.066 .01 \\
1.060 .01\end{array}$ & \\
\hline 1 & $3.436-30$ & & $1.06 \cdot 01$ & (2) \\
\hline & $\begin{array}{l}2.86 \cdot-20 \\
2.29 c-20\end{array}$ & & $\begin{array}{l}1.060-01 \\
1.060 \cdot 01\end{array}$ & \\
\hline & $1.20-30$ & & $1.06 \cdot 01$ & \\
\hline & $\begin{array}{l}1.55 \cdot 20 \\
: 5840-21\end{array}$ & & $\bigsqcup_{1.066-01}^{1.066-01}$ & \\
\hline & $\bigsqcup_{1.400 .23}^{5.984-21}$ & & & \\
\hline
\end{tabular}

\section{Case 2. (5\%-PVP 40-50 G/sterile water)}

2
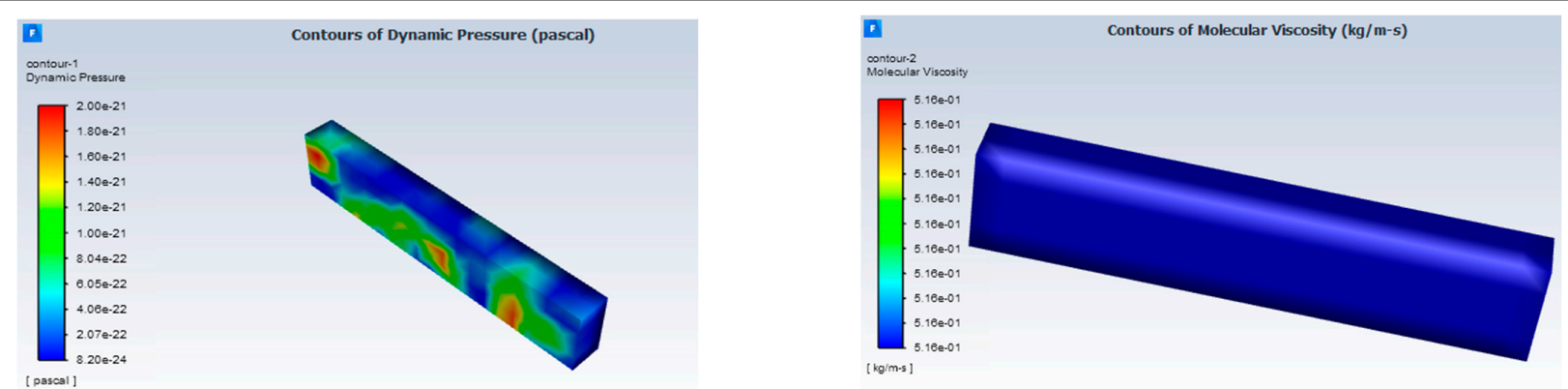
Table 3. Cont.

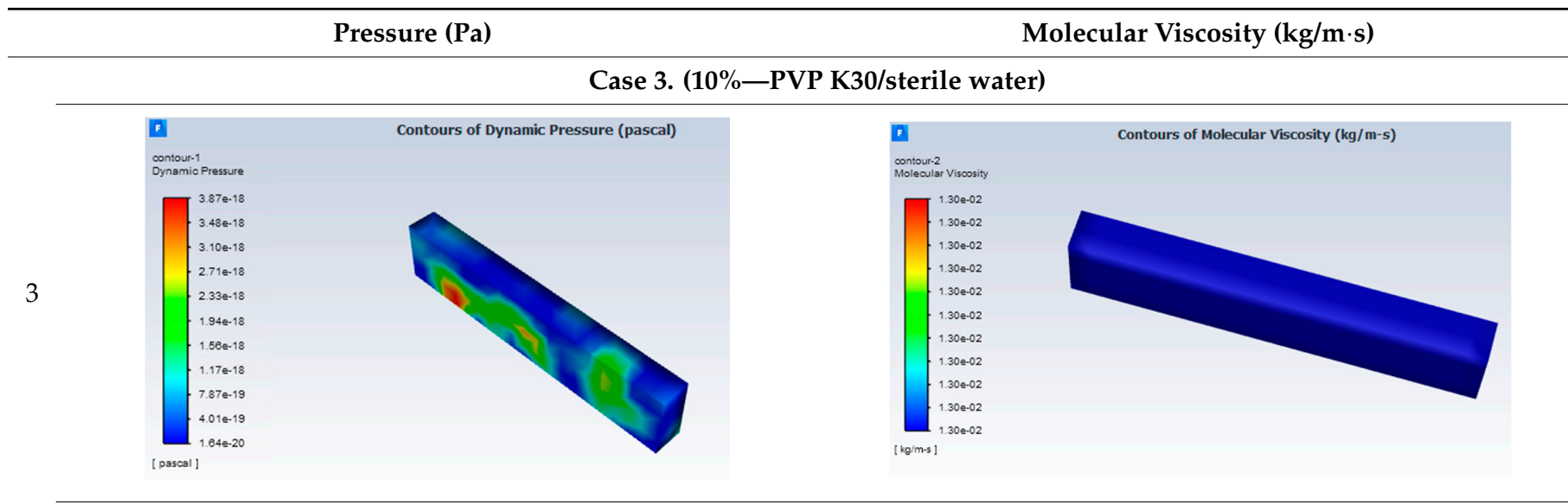

\section{Case 4. $(20 \%$-PVP40-50 G/sterile water)}

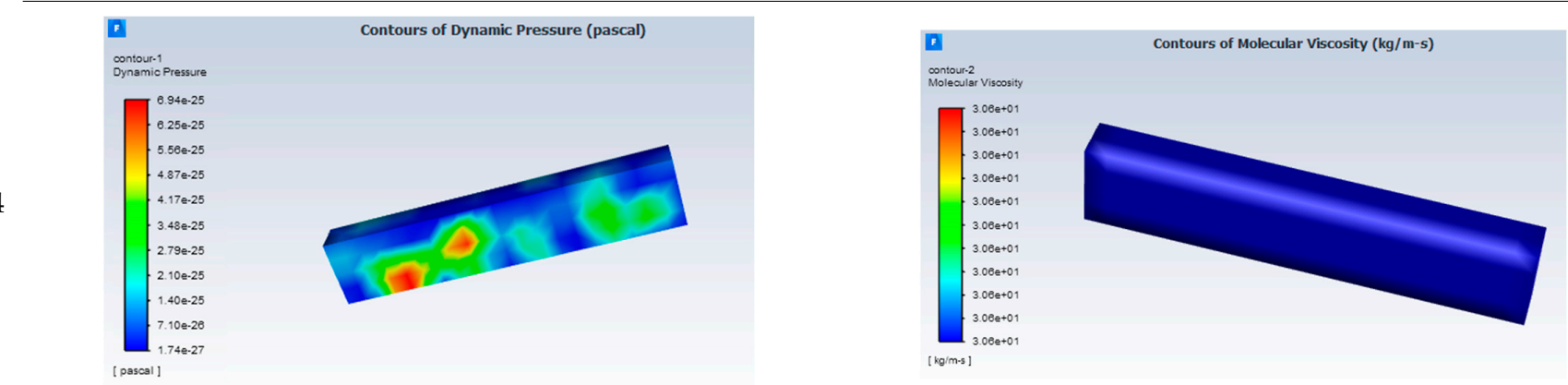

Case 5. (20\%-PVP K30/sterile water)

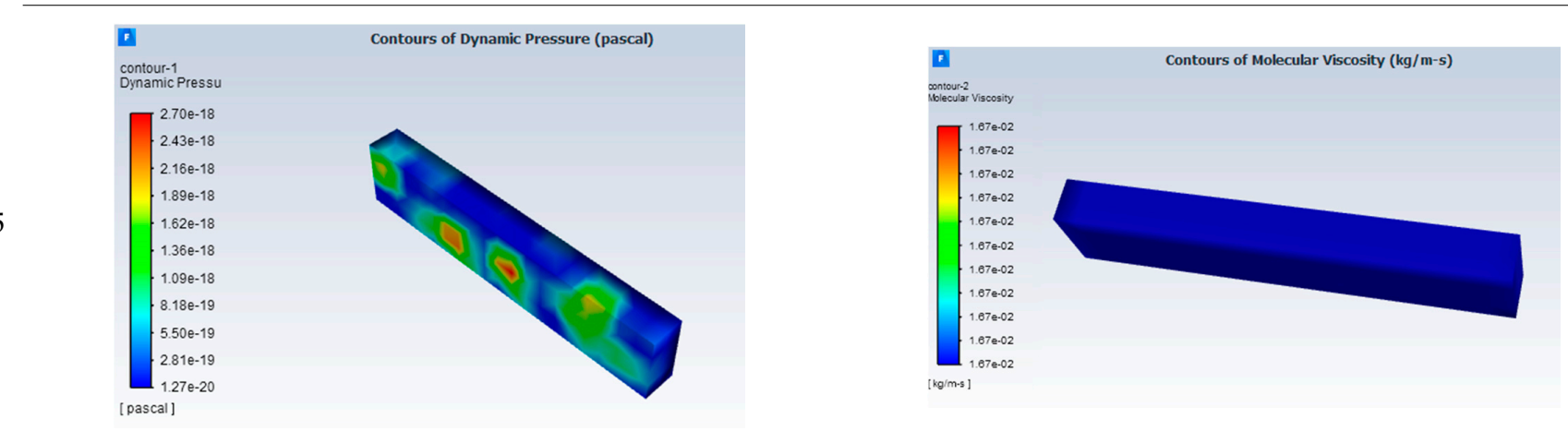

Table 4. Pressure and molecular viscosity values in each of the samples.

\begin{tabular}{cccc}
\hline Sample & Pressure Variation $(\mathbf{P a})$ & $\begin{array}{c}\text { Molecular Viscosity } \\
\mathbf{( k g / m \cdot s )}\end{array}$ & Residuals (Continuity) \\
\hline Sterile water & $4.132487 \times 10^{-23}$ to $1.084074 \times 10^{-19}$ & 0.10617 & $10^{-15}$ \\
\hline $5 \%$-PVP 40-50 G/sterile water & $3.906337 \times 10^{-24}$ to $3.642479 \times 10^{-21}$ & 0.51632 & $10^{-8}$ \\
\hline $10 \%$-PVP K30/sterile water & $6.383177 \times 10^{-21}$ to $5.806318 \times 10^{-18}$ & 0.01304 & $10^{-15}$ \\
\hline $20 \%$ PVP40-50 G/sterile water & $6.005832 \times 10^{-28}$ to $1.106963 \times 10^{-24}$ & 30.605 & $10^{-15}$ \\
\hline $20 \%$ PVP K30/sterile water & $2.921407 \times 10^{-21}$ to $5.371442 \times 10^{-18}$ & 0.01674 & $10^{-8}$ \\
\hline
\end{tabular}

Visual inspection of the dynamics pressure and molecular viscosity data shows different results. Although the properties of each of these solutions are different in each case, the variation in molecular viscosity remains unchanged compared to their initial value. It 
necessarily means that the viscosity across the rectangular volume remains the same for all of the solutions including sterile water. Since a uniform load in the stance phase is applied, in which case a boundary layer lubrication is observed, it is understandable that the fluid can depict such behavior for the molecular viscosity. However, the impact of the load is clearly observed in the case of dynamic pressure variation, where, even though the areas of impact are at similar locations, the order of their maximum and minimum values in terms of Pascal varied a lot.

From Table 4, it is observable that the dynamic pressure variation for PVP K30/sterile water remained in the order of $10^{-18}$ to $10^{-21}$ whereas the same for the PVP40-50 G/sterile water is of an even lower order, which is from $10^{-21}$ to $10^{-28}$. It means that the PVP K30 solutions displayed water-like behavior more than the solutions of PVP40-50 G. Case 1 is the simulation for sterile water. In this case, the pressure and molecular viscosity values of $4.132487 \times 10^{-23}$ to $1.084074 \times 10^{-19} \mathrm{~Pa}$ and $0.10617 \mathrm{~kg} / \mathrm{m} \cdot \mathrm{s}$ were observed, respectively. For case 2, the simulation results for 5\%-PVP 40-50 G/sterile water sample were calculated. It can be observed that in this case, the pressure and molecular viscosity values increased to $3.906337 \times 10^{-24}$ to $3.642479 \times 10^{-21} \mathrm{~Pa}$ and $0.51632 \mathrm{~kg} / \mathrm{m} \cdot \mathrm{s}$, respectively. Furthermore, for case 3, the 10\%-PVP K30/sterile water sample was selected. It was observed that in case 3 , the pressure and molecular viscosity reduced in the range $6.383177 \times 10^{-21}$ to $\mathrm{m}$ and $0.01304 \mathrm{~kg} / \mathrm{m} \cdot \mathrm{s}$, respectively. Case 4 and case 5 represent the pressure and molecular viscosity results for 20\%-PVP40-50 G/sterile water and 20\%-PVP K30/sterile water, respectively. It can be observed that the $20 \%$ - PVP40-50 G/sterile water sample has lower pressure and molecular viscosity ranges of $6.005832 \times 10^{-28}$ to $1.106963 \times 10^{-24} \mathrm{~Pa}$ and $30.605 \mathrm{~kg} / \mathrm{m} \cdot \mathrm{s}$ for pressure and molecular viscosity, respectively, as compared to the $20 \%$ PVP K30/sterile water sample, for which the values are in the range of $2.921407 \times 10^{-21}$ to $5.371442 \times 10^{-18} \mathrm{~Pa}$ and $0.01674 \mathrm{~kg} / \mathrm{m} \cdot \mathrm{s}$ for pressure and molecular viscosity, respectively.

\section{Conclusions}

The present study examined the rheological properties of PVP K30 and PVP 40-50 G solution samples, using an experimental and numerical approach. At lower shear rates, PVP 40-50 G/sterile water had a higher viscosity than PVP K30/sterile water. However, at higher shear rates, the PVP K30 sample produced better viscosity results, indicating that it is more suitable in terms of load carrying capacity. Numerical studies revealed the nature of boundary lubrication, with no variation in the molecular viscosities of each of the solutions. Aside from that, the results of the numerical study for PVP K30/sterile water corresponded to those of sterile water only, indicating a molecular level relationship between the two. Various future studies should focus on this agreement between the two and attempt to derive decisive reasons for it.

Author Contributions: Conceptualization, A.K. and I.E.S.; methodology, S.M.; software, A.Y. and T.V.S.Y.M.; validation, A.H.N. and G.R.; formal analysis, S.M.; investigation, S.M.; resources, A.Y., T.V.S.Y.M. and A.H.N.; data curation, A.Y. and G.R.; writing-original draft preparation, S.M. and A.Y.; writing-review and editing, A.K.; visualization, A.K.; supervision, A.K. and I.E.S.; project administration, A.K.; funding acquisition. All authors have read and agreed to the published version of the manuscript.

Funding: This research received no external funding.

Conflicts of Interest: The authors declare no conflict of interest.

\section{References}

1. Liao, J.; Miramini, S.; Liu, X.; Zhang, L. Computational study on synovial fluid flow behaviour in cartilage contact gap under osteoarthritic condition. Comput. Biol. Med. 2020, 123, 103915. [CrossRef] [PubMed]

2. Jay, G.D.; Waller, K.A. The biology of lubricin: Near frictionless joint motion. Matrix Biol. 2014, 39, 17-24. [CrossRef] [PubMed]

3. Cook, S.G.; Guan, Y.; Pacifici, N.J.; Brown, C.N.; Czako, E.; Samak, M.S.; Bonassar, L.J.; Gourdon, D. Dynamics of synovial fluid aggregation under shear. Langmuir 2019, 35, 15887-15896. [CrossRef] [PubMed]

4. More, S.; Kotiya, A.; Kotia, A.; Ghosh, S.K.; Spyrou, L.A.; Sarris, I.E. Rheological properties of synovial fluid due to viscosupplements: A review for osteoarthritis remedy. Comput. Methods Programs Biomed. 2020, 196, 105644. [CrossRef] [PubMed] 
5. Bhuanantanondh, P.; Grecov, D.; Kwok, E. Rheological study of viscosupplements and synovial fluid in patients with osteoarthritis. CMBES Proc. 2010, 33, 12-16. [CrossRef]

6. Lundsgaard, C.; Dufour, N.; Fallentin, E.; Winkel, P.; Gluud, C. Intra-articular sodium hyaluronate 2 mL versus physiological saline $20 \mathrm{~mL}$ versus physiological saline $2 \mathrm{~mL}$ for painful knee osteoarthritis: A randomized clinical trial. Scand. J. Rheumatol. 2008, 37, 142-150. [CrossRef] [PubMed]

7. Nair, B. Final report on the safety assessment of polyvinylpyrrolidone (PVP). Int. J. Toxicol. 1998, 17, 95-130. [CrossRef]

8. Haaf, F.; Sanner, A.; Straub, F. Polymers of N-vinylpyrrolidone: Synthesis, characterization and uses. Polym. J. 1985, 17, 143-152. [CrossRef]

9. Kurakula, M.; Rao, G.K. Pharmaceutical Assessment of Polyvinylpyrrolidone (PVP): As Excipient from Conventional to Controlled Delivery Systems with a Spotlight on COVID-19 Inhibition. J. Drug Deliv. Sci. Technol. 2020, 60, 102046. [CrossRef] [PubMed]

10. Radin, E.L.; Paul, I.L.; Weisser, P.A. Joint lubrication with artificial lubricants. Arthritis Rheum. Off. J. Am. Coll. Rheumatol. 1971, 14, 126-129. [CrossRef] [PubMed]

11. Bühler, V. Polyvinylpyrrolidone Excipients for Pharmaceuticals: Povidone, Crospovidone and Copovidone; Springer: Berlin/Heidelberg, Germany, 2005. [CrossRef]

12. Rowe, R.C.; Sheskey, P.; Quinn, M. Handbook of Pharmaceutical Excipients; Pharmaceutical Press: London, UK, 2009.

13. Frizon, F.; de Oliveira Eloy, J.; Donaduzzi, C.M.; Mitsui, M.L.; Marchetti, J.M. Dissolution rate enhancement of loratadine in polyvinylpyrrolidone K-30 solid dispersions by solvent methods. Powder Technol. 2013, 235, 532-539. [CrossRef]

14. Budavari, S.; O'Neil, M.J.; Smith, A. The Merck Index, 13th ed.; Merck \& Co. Inc.: Whitehouse Station, NJ, USA, 1996.

15. Kurakula, M.; Koteswara Rao, G.S.N. Moving polyvinyl pyrrolidone electrospun nanofibers and bioprinted scaffolds toward multidisciplinary biomedical applications. Eur. Polym. J. 2020, 136, 109919. [CrossRef]

16. Teodorescu, M.; Bercea, M.; Morariu, S. Biomaterials of PVA and PVP in medical and pharmaceutical applications: Perspectives and challenges. Biotechnol. Adv. 2019, 37, 109-131. [CrossRef] [PubMed]

17. Jun, Y.-B.; Min, B.-H.; Kim, S.-I.; Kim, Y.-I. Preparation and evaluation of acetaminophen tablets. J. Pharm. Investig. 1989, 19, 123-129.

18. Joint FAO/WHO Expert Committee on Food Additives. Technical Report Series; WHO: Geneva, Switzerland, 1987.

19. Guo, Y.; Hao, Z.; Wan, C. Tribological characteristics of polyvinylpyrrolidone (PVP) as a lubrication additive for artificial knee joint. Tribol. Int. 2016, 93, 214-219. [CrossRef]

20. Wong, Y.-R.; Sophie, S.H.T.; Mat Jais, I.S.; Leo, H.-L.; Liu, C.-F.; Tay, S.-C. Computational Simulation of Synovial Fluid Kinematics of the Scapholunate Joint. J. Hand Surg. 2019, 24, 169-174.

21. Wang, Y.; Fan, Y.; Zhang, M. Comparison of stress on knee cartilage during kneeling and standing using finite element models. Med. Eng. Phys. 2014, 36, 439-447. [CrossRef] [PubMed] 